\title{
Contributions to the development of a methodology for determining the flow rate
}

\author{
Cristian Purece ${ }^{1}$, Valeriu Panaitescu ${ }^{2}$, Irina Alina Chera Anghel $^{1}$ \\ ${ }^{1}$ Energy Research and Modernization Institute - ICEMENERG, Bucharest, România \\ ${ }^{2}$ University Politehnica of Bucharest, Power Engineering Faculty, Bucharest, România
}

\begin{abstract}
The implementation of the requirements of the European Parliament Directive 2009/28 / EC requires efficient use of the water supply of a hydropower plants installation in order to obtain a higher amount of electricity by producing the same volume of water. In order to achieve efficient utilization of the energy of the water is necessary framing the operation of hydropower plants in the ranges of head course and the electric power so that the energy conversion is carried out in the optimum efficiency characteristic operation of the system. In order to determine as accurately the actual operating characteristics of a hydro- unit, in situ tests are required to determine the actual operating parameters of the hydrounit. These parameters, the flow rate is the parameter that requires the most complex methodologies to determine. The paper presents a way of improvement but also a simplification of the methodology for in situ determination of the flow to small hydropower plants by using a mobile frame that has implemented a wireless data transmission system.
\end{abstract}

\section{Introduction}

The purpose of this paper is to obtain a modern methodology for in situ determination of the flow rate at small hydropower plants, but also in other locations such as open channels, etc. Depending on the in-situ flow rate, the actual performance characteristics of the turbine and the hydro-unit will be plotted.

The operation of the hydro-unit in the optimal operating areas established according to the actual performance characteristics will have the effect of increasing the hydro-unit efficiency.

The operation of the hydropower development and hydro-unit at any time is characterized by certain values of their characteristic parameters, $Q$ flow rate, $H$ head, $P$ power, $\eta$ efficiency, etc. The correlation between the values of these parameters within their entire range of variation, determined by the type, construction, and dimensions of the arrangement, is graphically defined by the so-called characteristic curves of the arrangement or of the hydro-unit (HA) equipping a hydropower plant (turbines, pumps, etc.).

Characteristic curves, areas or optimal operation lines are determined from the design process. Due to the cover reserves necessarily taken into the project and due to the specificity of the execution, the actual curves differ not only from the projected ones but also from the hydro-unit to the hydro-unit, even if they were executed by the same performer on the same object. The modern measurement theory and technique allows the 
individuality of each unit to be determined individually, which creates the necessary premises for knowing and using both the internal reserves resulting from the project coverage of the hydro-unit and the differences between hydro-unit of the same hydropower plant, optimal differential use of hydro-aggregates. The optimal operation of a hydro-unit, a power plant, or a cascade of power plants is equivalent to an increase in energy or the existence of some (theoretical) hydropower development that would have an additional $2 \%$ of additional electricity production.

In order to obtain a maximum of electricity production, it is necessary for a multi-group hydroelectric plant to operate at the optimum parameters.

This means that hydro-unit are operating in the maximum efficiency areas (which are usually not at the maximum power of the hydro-unit) and the hydropower works with minimum head losses (with a minimum flow) under the conditions of a power imposed on the plant. Of the parameters of a hydro-unit, the parameter whose determination poses the most difficult problems is the flow rate. Determining this parameter requires a complex measurement methodology.

The main methods of determination of the flow rate for hydropower plants are provided in the international standards for in situ measurements [1], [2], [3].

The current meter method is one of the most appreciated and precise methods of flow rate determination, and the only recommended method for determining the flow rate at a low head hydropower plant.

This paper aims to improve and simplify the methodology for determining the flow rate at a small hydropower plant by using an adjustable mobile frame.

Simplifying the methodology for determining the flow rate and energy performance of hydro-units in the hydropower plant will reduce the time required to conduct in situ determinations and lower the cost of performing energy performance tests.

\section{Description of the measurement method used}

The current meter method consists into place in a circular, rectangular or trapezoidal section of a number of measuring transducers (current meter, Pitot tubes or acoustic transducers) to determine the water velocity at those points, is known in the literature as "punctual speed". The actual flow profile in the measurement section can only be traced using the current meter or Pitot tubes and to a certain extent using the acoustic method, but only when multiple measurement paths are used. The flow rate in a trapezoidal or rectangular section for a $d x \cdot d y$ elemental surface can be written as [4]:

$$
\mathrm{d} Q=v(x, y) \mathrm{d} x \mathrm{~d} y
$$

For the entire measuring surface the flow is calculated using the formula:

$$
Q=\sum_{i} v_{i} \Delta x_{i} \Delta y_{i}
$$

written in full form the flow calculation formula for the entire measuring surface is:

$$
Q=\iint_{S} v(x, y) d x d y
$$

The relation (7) can be expressed in the form of a simple integral in two ways:

$$
Q=\int_{0}^{x} d x \int_{0}^{y} v d y \quad \text { or } \quad Q=\int_{0}^{y} d y \int_{0}^{x} v d x
$$


The calculation of the integral (8) can be done with the spline or cubic spline interpolation function [5], with Lagrange interpolation polynomials or the Simpson integration method [6]. In order to trace the distribution of speeds in the border area it is taken into account that from the walls to the first moose the velocity can be expressed by the law of Kármán [7]:

$$
v_{x}=v_{a}\left(\frac{x}{a}\right)^{1 / n}
$$

where $v_{x}$ is the velocity in the extrapolation zone at a distance $x$ from the section wall, - the velocity at the nearest point to the section wall, and $\mathrm{n}$ is a coefficient which takes into account the roughness of the wall, the flow conditions and apply near the walls and radiator, when there are no special contraindications, it can be considered $n=7$. The extraction from the marsh on the free surface of the water is based on observing the continuity of the curve drawn. If the surface velocity is also measured with floats, the account is taken of its value.

\section{Description of the measurement system used}

The proposed mobile measurement system (Figure 1) will be used for the determination of the absolute flow rate and calibration of the differential pressure inlet on the spiral chamber of the hydraulic turbines in the low head hydropower plants [8] is presented below.

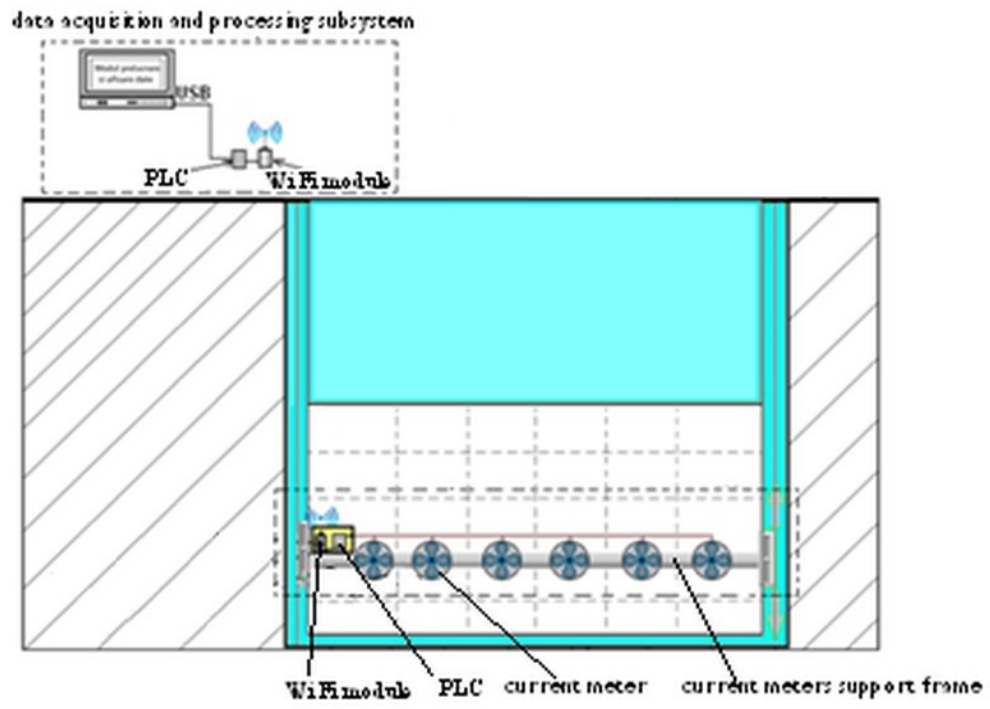

Fig. 1. Structure the mobile system of the flow rate in situ measurement

This mobile system will consist of a series of current meters, a modular mobile frame (necessary for the installation of current meters in safe conditions at points with fixed coordinates and their arrangement in the measurement section), a smart data acquisition interface represented by a PLC (automatically programmable), two wireless data transmission modules, a computing unit featuring a powerful laptop that will allow calculating and displaying in situ on the monitor of the computing unit of interest sizes.

On the monitor of the computing unit, the values of measured magnitudes measured by the current meters and the individual velocity, the calculated flow rate and average values in the measurement section, the graph of the velocity distribution in the measurement 
section, the information shall be stored in the the database (previous measurements, the parameters of the current meters and the turbine / hydro-units where the measurements were made, etc.). The mobile frame used to place the current meters is a modular frame (Figure 2) consisting of several segments and can be adapted for different dimensions of the flow measurement sections. Also, the modular mobile frame can be easily assembled and is easy to transport and handle, it is much easier than a classical hydrometric frame made up of a single component.

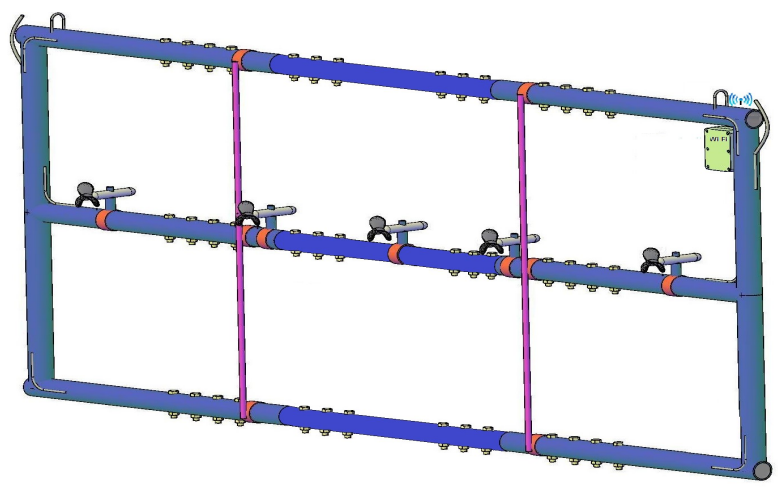

Fig. 2. 3D draw mobile frame support the current meters

Replacing the classic mode of multi-wire electric cable transmission of electrical signals purchased from current meters through the use of a wireless data transmission system is another advantage of the proposed measuring mobile system. Using wireless data transfer mode will allow you to reduce the working time required to mount the current meter on the support frame, thus reducing the downtime of the hydro unit. The location of the mobile system to measure in situ flow rate to low head hydropower is intake entrance in stop logs upstream of the hydraulic turbine.
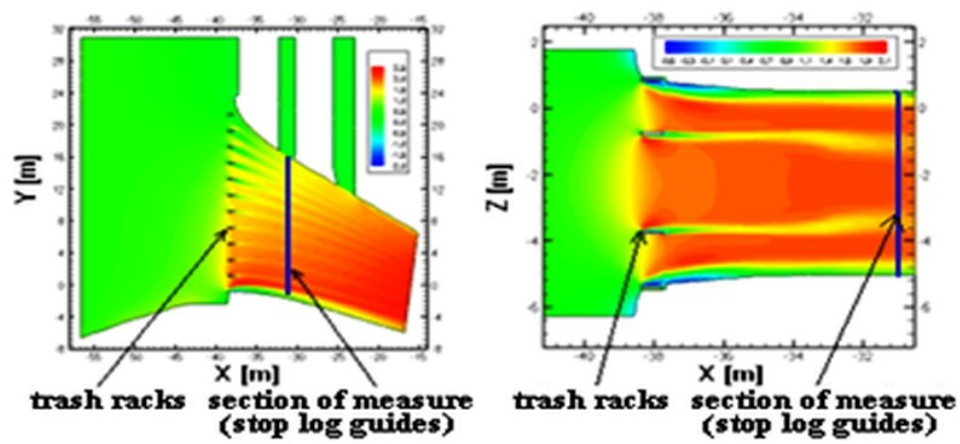

Fig. 3. The flow rate measurement section for low head hydropower plants

Figure 3 shows the location section of the flow rate measurement system for low head hydropower plants in the XY and XZ co-ordinates (9).

\section{Results and discussions}

In order to verify the operation of the flow rate measurement mobile system, both laboratory and in situ samples were performed. 
The in situ samples were carried out at Zăneşti HPP, a low head hydropower plant located on the Bistriţa River.

Zăneşti HPP (figure 4) consists of two Kaplan turbines of the type 7.5-20 with a $20.2 \mathrm{~m}$ gross head, a power installed on the hydropower plant of $15.5 \mathrm{MW}$ and a flow rate installed on the hydropower plant of $84 \mathrm{~m} 3 \mathrm{~s}-0,5$ and production of electricity of $81.5 \mathrm{GWh} /$ year.

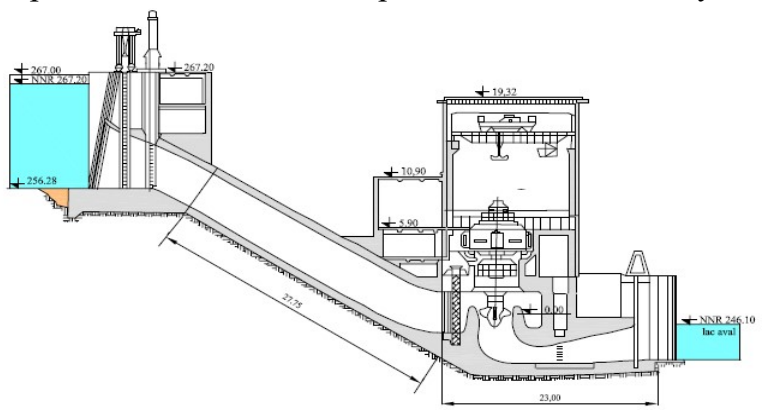

Fig. 4. Cross section through Zăneşti HPP

For the determination of the flow rate the current meter method was used, and the measuring section was the stop logs upstream of the turbine from the hydropower plants unit HA1 from Zăneşti HPP. Gross head and power on the plant were kept constant throughout the sample.

Samples were performed for a $3 \mathrm{MW}$ power to the hydro-generator from the HA1 and a gross head of $19.1 \mathrm{~m}$.

After the flow measurements in the stop logs upstream of the HA1, the following average velocities and flows were obtained:

- for the left stop logs an average velocity $v_{\mathrm{m} 1}=0.733[\mathrm{~ms}-1]$ and an average flow rate $Q_{\mathrm{m} 1}=10.561[\mathrm{~m} 3 \mathrm{~s}-1]$;

- for the right stop logs an average velocity $v_{\mathrm{m} 2}=0.583[\mathrm{~ms}-1]$ and an average flow rate $Q_{\mathrm{m} 2}=8.391[\mathrm{~m} 3 \mathrm{~s}-1]$;

- for HA1 an average velocity $v_{\mathrm{m}}=0.658$ [ms-1] and an average flow $Q_{\mathrm{m}}=18.952$ [m3s-1].

After performing of the measurements, a real picture of the velocity distribution in the two stop logs upstream of the HA1 turbine was obtained. 3D distribution of velocity measured with the mobil frame in the two of turbine stop logs according to the height $(H)$ and the length $(L)$ the measurement section is shown in Figures 5 and 6, [10].
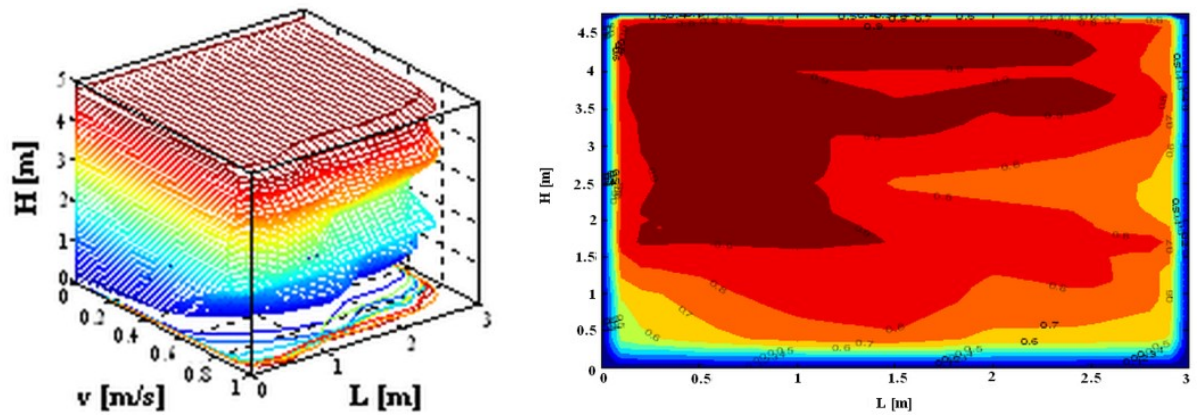

Fig. 5. The distribution of the velocity and lines of equal velocity, left stop logs at HA1 

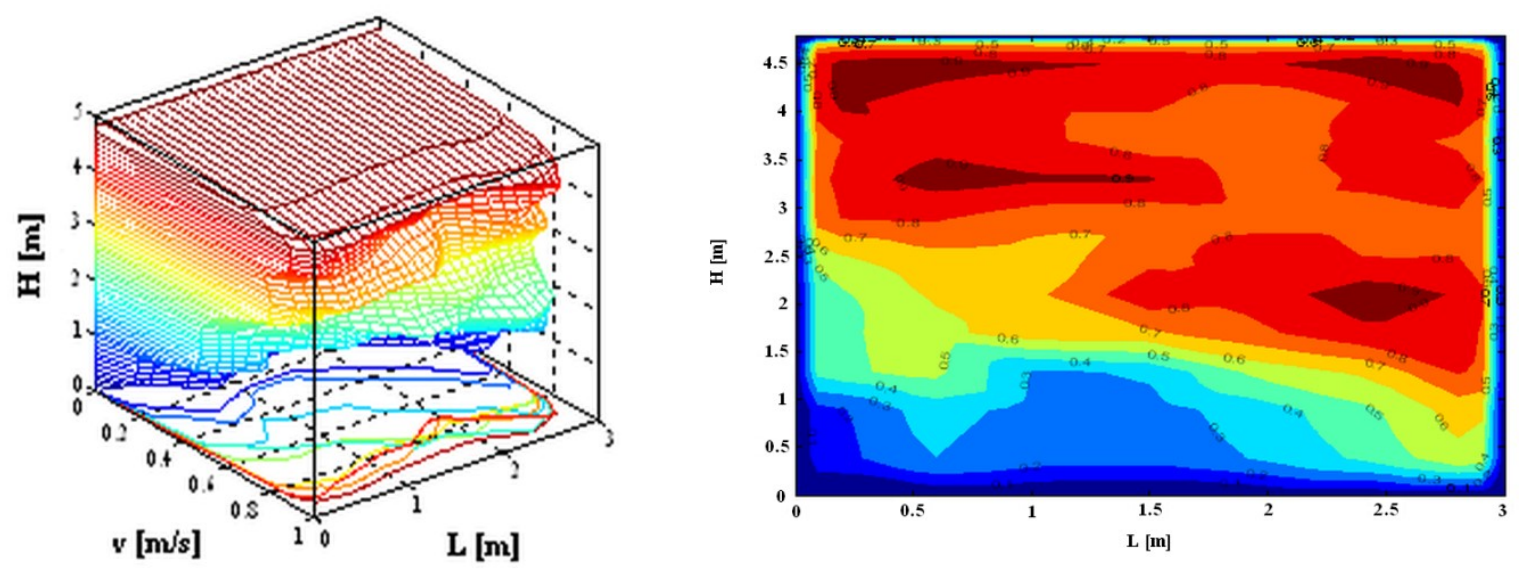

Fig. 6. The distribution of the velocity and lines of equal velocity, right stop logs at HA1

After performing the tests in situ, was calculated based on relationship (6) the turbine efficiency and were drawn the actual turbine operating characteristic $\eta_{T}=\mathrm{f}\left(P_{T}\right)$ for HA1 (figure 7).

$$
\eta_{T}=\frac{102 P_{T}}{H_{n} Q}
$$

where: $P_{\mathrm{T}}$ is the turbine power, $\eta_{T}$ is the turbine efficiency, $Q$ is the flow, $H_{\mathrm{n}}$ is the net head.

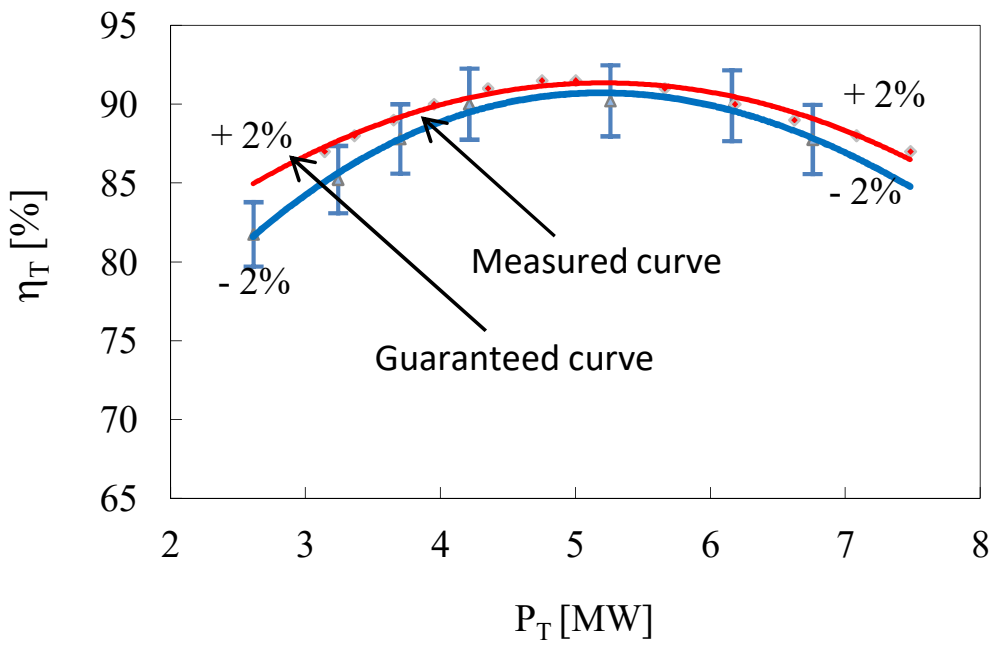

Fig. 7. The turbine efficiency characteristic according to turbine power $\eta_{\mathrm{T}}=\mathrm{f}\left(P_{\mathrm{T}}\right)$ for $\mathrm{HAl}$

As can be seen from Figure 7, the optimal operating range of the turbine from HA1 is between 3.75 MW and 6.70 MW, the field in which the turbine operates at a yield of at least $88 \%$. The error of determination of the flow was $1.1 \%$ and the calculation error of the actual performance of the hydraulic turbine obtained by the current meter method was $\pm 1,4$ $\%$, lower than the limit of $\pm 2 \%$ provided in the standard CEI 41/1991. 


\section{Conclusions}

The aim of the paper was to simplify the methodology for in situ determination of the flow and to increase the accuracy of flow determination by using an absolute measurement method, current meter method.

The novelty of the methodology is to use in the mobile system the in situ measurement of the flow of a modular mobile frame for the location of current meter in the measurement section of a wireless data transmission system and a specialized flow calculation program. The use of the modular mobile frame instead of the fixed class frame and the Wireless system will reduce the time required to mount the current meter on the frame and reduce the number of current meters used. Also, with the help of the computing program, the flow will be calculated in situ using one or more calculation methods, which will increase the accuracy of the in-situ flow rate methodology. The modular mobile frame used in the mobile system is unique in Romania.

It has been designed to determine the flow rate for hydropower plants but can also be used in other locations (open channels, thermal power plants) and can be modified according to the measurement section. The mobile system for flow determination proposed in this paper can be used periodically for the determination of the flow rate and calibration of the pressure tape of the hydraulic turbine spirals in hydropower plants, in order to achieve a flow rate measurement permanent installation and as a benchmark for other methods flow measure, such as acoustic transit time method, acoustic scintillation method, Gibson method [11].

A general conclusion of this paper is that the simplification and improvement of the flow rate measurement methodology using the current meter is feasible. The solutions proposed in this paper are viable and perfectly applicable in the usual practice, resulting in the simplification the methodology for in situ flow determination and lower its cost price.

The research proposed in this paper can be continued by testing a mobile system for in situ flow rate determination using a mobile frame that has implemented a device capable of modifying the angle of location of the current meters depending on the flow spectrum in the measurement section, such that that the angle between the current meter axis and the tangent to the current lines of the flow spectrum to be max. $5^{0}$. The use of this device will eliminate the error introduced in the flow calculation by the angle between the axis of the current meters and the tangent to the current lines of the flow spectrum, error encountered in the flow measurements performed with the current meters placed on a mobile frame.

\section{References}

[1] *** ASME PTC 18, American National Standard - Hydraulic turbines and pumpturbine performance test codes. New York, USA, ASME (2002) (consolidation of ASME PTC 18-1992 and ASME PTC 18.1-1978)

[2] *** CEI 41/1991 - Field acceptance tests to determine the hydraulic performance of hydraulic turbines, storage pumps and pumps-turbines. Geneva, Switzerland, CEI $3^{\text {rd }}$ edition, (1991)

[3] $* * *$ CEI 62006/2010 - Hydraulic machines. Acceptance tests of small hydroelectric installations. Geneva, Switzerland, CEI $1^{\text {st }}$ edition, (2010)

[4] A. Adamkowski, Essential methods of SHP efficiency testing. Keynote address at the SHP Research\& Development Actors Network Meeting, The Szewalski Institute of Fluid-Flow Machinery, Gdansk, September 10-11th, (2009)

[5] Z. Krzemianowski, A. Adamkowski, Use of Non-uniform Rational B-splines for Discharge Calculation in the Velocity Area Method. Journal of Energy and Power Engineering 8, pp. 911-919, (2014) 
[6] $* * *$ ISO 3354/2008 - Measurements of clean water in closed conduits. Velocity-area method using current-meters in full conduits and under regular flow conditions. ISO $3^{\text {rd }}$ edition (2008)

[7] J. Steller, A. Adamkowski, A. Henke, W. Janicki, Discharge measurement and performance tests of hydraulic units in low-head small hydropower installations, Transactions of the Institute of Fluid-flow Machinery, No. 130, pp. 3-29, (2015)

[8] *** INCDE ICEMENERG, Researches on the higher use of water resources by new solutions for measuring turbine flow at hydropower plants, contr. MCI nr. 20 N/2016, Bucureşti (2016)

[9] G. Proulx, E. Cloutier E., Comparasion of discharge measurement by current meter and acoustic scintillation methods at La Grande-1, Proc. IGHEM, Lucerne Switzerland, (2004)

$[10] * * *$ INCDE ICEMENERG, Determination of performance parameters of the hydro units in Zăneşti HPP, contr. Hidroelctrica nr. 18/2015, Bucureşti (2015)

[11] D. Gonzales, F. Murciaccia, Turbine acceptance tests at Frieira HPP, Mino River, Spain with Acoustic Scintillation Flow Meters and current meters. Proc. HydroVision, Denver USA (2013) 